
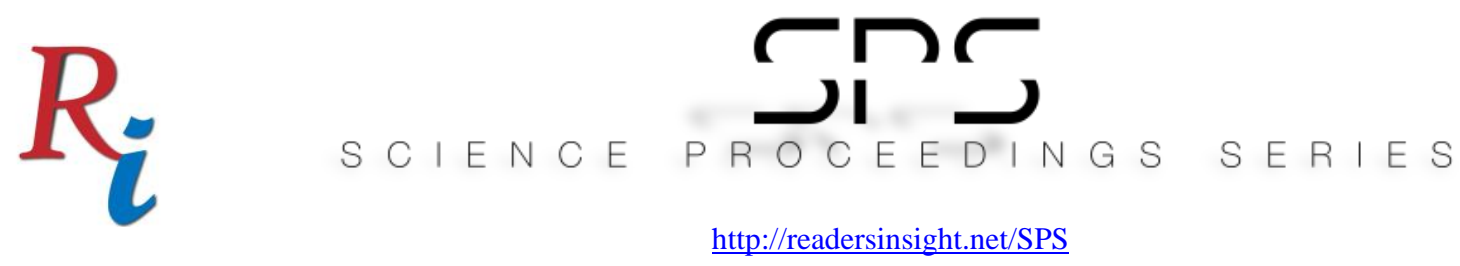

\title{
EFFECT OF SNPS IN BCL11A GENE ON THE CLINICAL HETEROGENEITY OF THE PATIENTS WITH HBE/BETA- THALASSEMIA IN BANGLADESH
}

\section{Subarna Sayed Ety ${ }^{\mathbf{T}}$}

Department of Genetics and Genomics, Institute for Developing Science and Health Initiatives (ideSHi), Bangladesh subarnasayed09@gmail.com

\section{Farjana Akther Noor $^{\mathrm{T} *}$}

Institute for Developing Science and Health Initiatives (ideSHi)

Departement of Biochemistry and Molecular Biology, University of Dhaka, Bangladesh farjana@ideshi.org

\section{Mohabbat Hossain}

Department of Genetics and Genomics

Institute for Developing Science and Health Initiatives (ideSHi), Bangladesh mohabbat@ideshi.org

\section{Suprovath Kumar Sarker}

Institute for Developing Science and Health Initiatives (ideSHi)

Departement of Biochemistry and Molecular Biology, University of Dhaka, Bangladesh

s.suprovath@gmail.com

\section{Syed Saleheen Qadri}

Department of Genetics and Genomics

Institute for Developing Science and Health Initiatives (ideSHi), Bangladesh ssqadri@gmail.com

Kaiissar Mannoor

Department of Genetics and Genomics Institute for Developing Science and Health Initiatives (ideSHi), Bangladesh kaiissar@ideshi.org

*Corrosponding author's Email: farjana@ideshi.org

${ }^{\mp}$ These authors contributed equally to this work.

Peer-review under responsibility of 4th Asia International Multidisciplinary Conference 2020 Scientific Committee http://connectingasia.org/scientific-committee/ (C) 2020 Published by Readers Insight Publisher, lat 306 Savoy Residencia, Block 3 F11/1,44000 Islamabad. Pakistan,

editor@readersinsight.net 

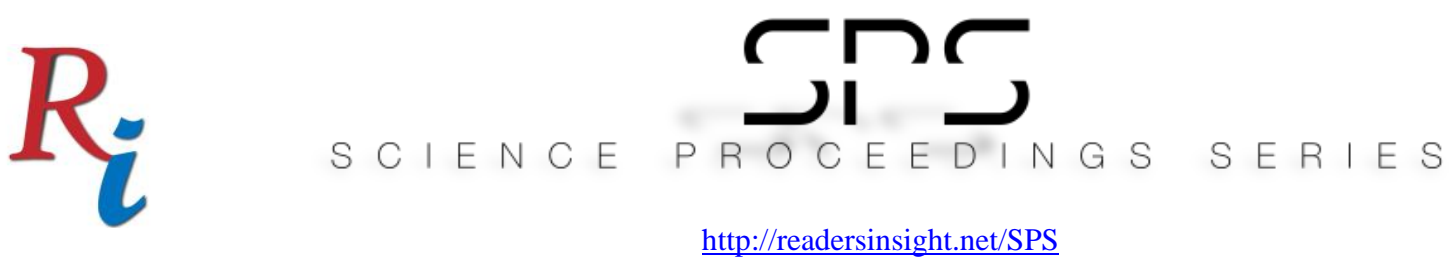

\section{A b s t r a c t}

Hemoglobin $E / \beta$-thalassemia is a blood disorder with highly variable clinical phenotypes. Increased production of fetal hemoglobin $(\mathrm{HbF})$ can influence the degree of severity in $\beta$ thalassemia. This study aimed to unravel the disease modifying effects of two SNPs, $r s 4671393$ \& rs 11886868 in BCL11A gene among $\mathrm{HbE} / \beta$-thalassemia patients. A total of $133 \mathrm{HbE} / \beta-$ thalassemia patients with mean of age 19.66 10.22 years and 50 healthy controls with completely normal hematological parameters were recruited in this study and patients were classified as NTD/mild, moderate and severe, according to previously reported clinical scoring system. Laboratory investigation included hematological tests using Complete Blood Count analysis and Hemoglobin elctrophoresis; SNPs were detected by High Resolution Melt-Curve (HRM) analysis based on Real-time PCR and Sanger Sequencing. The allelic distribution of $r s 4671393$ was $78.2 \% \mathrm{GG}$ and $21.8 \% \mathrm{AG}$; and for $r s 11886868,51.12 \% \mathrm{CC}$ and $48.9 \% \mathrm{CT}+\mathrm{TT}$ among the patients. Both SNPs showed significant association with induction of $\mathrm{HbF}$ in $\mathrm{HbE} / \beta$ thalassemia patients, while $r s 4671393$ showed no signifant effect on severity score. HbF level was significantly correlated with transfusion interval and clinical score while showed comparatively less correlation with the age of first blood transfusion. However, any of the two SNPs showed no HbF inductive effect in the absence of anemic condition.

\section{Rese a r ch H i g h I igh t s}

Highlight-1: Among the $\mathrm{HbE} / \beta$-thalassemia patients in Bangladesh, the minor allele frequency of $r s-4671393(\mathrm{~A})$ and $r s-11886868(\mathrm{~T})$ in the BCL11A gene was found as 0.11 and 0.25 respectively.

Highligtht-2: Minor alleles of both SNPs showed significant association with induction of $\mathrm{HbF}$ ( $p=0.02, p=0.03$ respectively) in $\mathrm{HbE} / \beta$-thalassemia patients. On the other, only the $r s$ 11886868 (T) allele was found to have satistically significant lowering effect on the disease severity of the patients.

Highlight-3: HbF level was positively correlated $(\mathrm{r}=0.5)$ with transfusion interval and negetively correlated to clinical score $(\mathrm{r}=-0.45)$ impling that increased production of $\mathrm{HbF}$ decreases the rate of blood transfusion as well as disease severity in $\mathrm{HbE} / \beta$-thalassemia patients.

Highlight-4: In spite of having both SNPs (17\% minor allele for $r s-4671393$ and $25 \%$ minor allele for $r s-11886868)$, no induction of $\mathrm{HbF}$ was found among SNPs positive healthy individuals. 

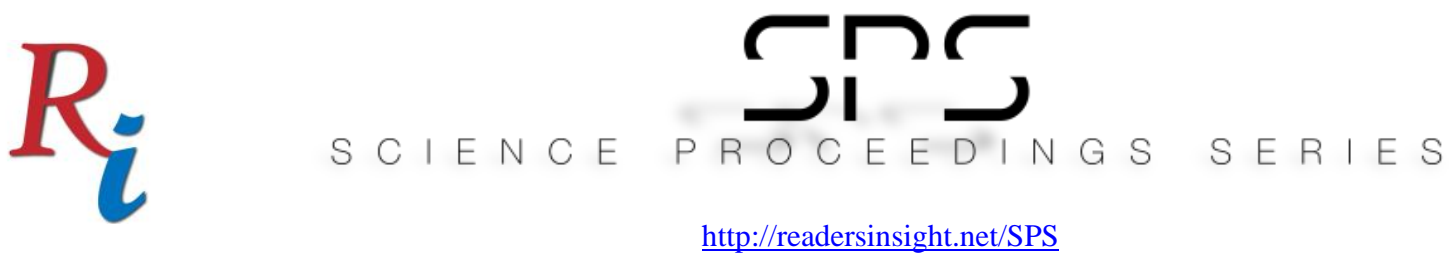

\section{Research Objectives}

$\mathrm{HbE} / \beta$-thalassemia is an inherited hemolytic disease highly prevalent in Bangladesh as the carrier frequency of $\mathrm{HbE}$ and $\beta$-thalassemia traits are very high ( $8.68 \%$ and $2.24 \%$ respectively) in the population [1]. Increased level of $\mathrm{HbF}$ has been reported as an influencing phenotypic factor of $\mathrm{HbE} / \beta$-thalassemia and genom-wide studies have identified a number of single nucleotide polymorphisms (SNPs) within the gene of repressor protein BCL11A associated with elevated $\mathrm{HbF}$ levels [2,3]. This study aimed to evaluate whether genetic variability at BCL11A locus influences $\mathrm{HbF}$ levels in $\mathrm{HbE} /$ beta-thalassemia patients in Bangladesh. In particular, to determine the frequency of two SNPs, rs $11886868 \&$ rs4671393 at BCL11A gene and their association with increased production of $\mathrm{HbF}$, thus the effect on the clinical heterogeneity among the patients with $\mathrm{HbE} /$ beta-thalassemia in Bangladesh. So far, it is the first study on BCL11A gene polymorohisms done in Bangladesh. In the former decades, the main inclination of research was $\mathrm{HbF}$ induction since ascending $\mathrm{HbF}$ levels uplift the severity of $\beta$-thalassemia and $\mathrm{HbE} / \beta$-thalassemia in adults [5,6]. Targeting BCL11A gene for gene editing to reactivate fetal hemoglobin gene expression in the $\mathrm{HbE} / \beta$-thalassemia patients, our study confers indispensable knowledge for developing targeted potential therapies hereafter.

\section{Methodology}

From Bangladesh Thalassemia Samity Hospital in Dhaka, a total of $133 \mathrm{HbE} / \beta$-thalassemia patient with a mean of age $19.66 \pm 10.22$ years were enrolled in this study $(56.4 \%$ male and $43.6 \%$ female). All laboratory analysis were performed at "Institute for Developing Science and Health Initiatives (ideSHi)" laboratory providing BSL-2 facilities. Ethical approval was provided by the 'Bangladesh Medical Research Council (BMRC)' for this study. Blood ( $5 \mathrm{~mL})$ of patients were collected from venous just before blood transfusion and subjected to $\mathrm{CBC}$ analysis by 'automated hematology analyzer Sysmex kx-21' (Sysmex Corporation, Kobe, Japan) and hemoglobin electrophoresis by 'CAPILLARYS 2 instrument (Sebia, France)'. For molecular analysis, DNA isolation from patients whole blood cells using 'FlexiGene DNA kit' (QIAGEN, Hilden, Germany) and Polymerase Chain Reaction using 'Qiagen HotStart Taq DNA Polymerase' (Qiagen, USA) were done carefully. Sanger Nucleotide Sequencing was performed to detect the SNPs for the first time and to use those as reference samples. Then for SNPs detection, HRM analysis based on Real-time PCR were accomplished on 'BioRad CFX96 Touch Real-Time System' by using 'Precision Melt Analysis ${ }^{\text {TM }}$ Software (BioRad)' according to manufacturer's instruction and statistical analysis including two-tail unpaired Ttest, one-way ANOVA test and Pearson Correlation were done using 'Graphpad Prism-version 7 . 


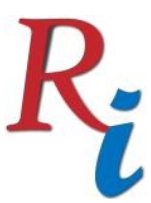

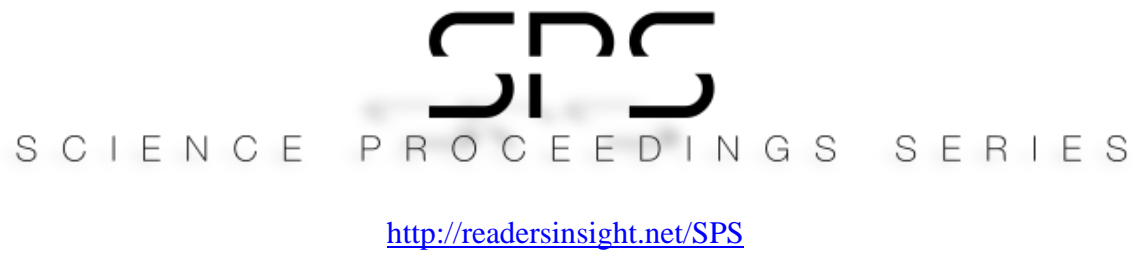

http://readersinsight.net/SPS

\section{Results}

The patients were divided into three groups- Non Transfusion Dependent (NTD)/mild, moderate and severe according to the previously reported scoring system with little modification [4]. HbF level was significantly higher $(p<0.0001)$ in NTD/mildly severe group compared to other two groups. Extracted genomic DNA from 133 patients and 50 healthy controls were analyzed for detection of two SNPs at the BCL11A gene, namely rs4671393 and rs 11886868 which have been reported to have significant association with elevated level of $\mathrm{HbF}$ in adults in several studies [2,3]. Among the patients, the allelic distribution of $r s 4671393$ was $78.2 \% \mathrm{GG}, 21.8 \% \mathrm{AG}$ and for $r s 11886868$, there were $51.12 \% \mathrm{CC}$ and $48.9 \% \mathrm{CT}+\mathrm{TT}$. Both SNPs showed significant association with induction of $\mathrm{HbF}(\mathrm{g} / \mathrm{dl})(p=0.03$ and $p=0.02)$ in the $\mathrm{HbE} /$ beta-thalassemia patients. However, clinical severity score was significantly lower in the patients only in $r s 11886868(p=0.03)$ carrying the minor allele T. Pearson Correlation analysis revealed significant correlation of $\mathrm{HbF}$ with transfusion interval $(r=0.5)$ and clinical score $(r=-0.45)$, and comparatively less correlation with the age of first blood transfusion $(r=$ 0.32). In spite of having both SNPs (17\% minor allele for $r s 4671393$ and $25 \%$ minor allele for rs 11886868), no induction of $\mathrm{HbF}$ was found among SNPs positive healthy individuals.

\section{Findings}

The two SNPs of BCL11A rs 11886868 and $r s 4671393$ have significant effect on increased fetal hemoglobin level in the adult patients with $\mathrm{HbE} / \mathrm{beta}$-thalassemia in Bangladesh and thus shows similarity with the previous studies done on other populations. Though rs4671393 showed no significant association with clinical severity of the patients, the mean value of the clinical score was much lower in the patients groups carring the minor alleles. Moreover, pearson correlation test showed that high level of $\mathrm{HbF}$ decreases blood transfusion rates and clinical scores in the patients, thus both SNPs can be correlated with less severity of the disease.

\section{REFERENCES}

[1] Noor FA, Sultana N, Bhuyan GS, Islam MT, Hossain M, Sarker SK, et al. Nationwide carrier detection and molecular characterization of $\beta$-thalassemia and hemoglobin $\mathrm{E}$ variants in Bangladeshi population. Orphanet Journal of Rare Diseases. 2020;15(1):15. https://ojrd.biomedcentral.com/articles/10.1186/s13023-020-1294-Z

[2] Rujito L, Basalamah M, Siswandari W, Setyono J, Wulandari G, Mulatsih S, et al. Modifying effect of XmnI, BCL11A, and HBS1L-MYB on clinical appearances: a study on $\beta$-thalassemia and hemoglobin $E / \beta$-thalassemia patients in Indonesia. Hematology/oncology and stem cell therapy. 2016 Jun 1;9(2):55- 

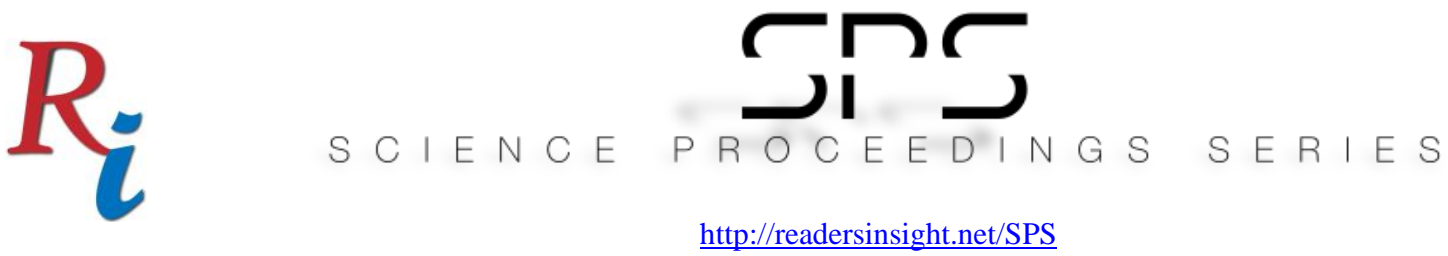

63.https://www.sciencedirect.com/science/article/pii/S1658387616300036?via\%3Dihu $\underline{b}$

[3] Dadheech S, Madhulatha D, Jain S, Joseph J, Jyothy A, Munshi A. Association of BCL11A genetic variant (rs11886868) with severity in $\beta$-thalassaemia major \& sickle cell anaemia. The Indian journal of medical research. 2016 Apr;143(4):449. https://www.ncbi.nlm.nih.gov/pmc/articles/PMC4928551/

[4] Sripichai O, Makarasara W, Munkongdee T, Kumkhaek C, Nuchprayoon I, Chuansumrit A, Chuncharunee S, Chantrakoon N, Boonmongkol P, Winichagoon P, Fucharoen S. A scoring system for the classification of $\beta$-thalassemia/Hb E disease severity. American journal of hematology. 2008 Jun;83(6):482-4. https://onlinelibrary.wiley.com/doi/abs/10.1002/ajh.21130

[5] Bauer DE, Kamran SC, Lessard S, Xu J, Fujiwara Y, Lin C, Shao Z, Canver MC, Smith EC, Pinello L, Sabo PJ. An erythroid enhancer of BCL11A subject to genetic variation determines fetal hemoglobin level. Science. 2013 Oct 11;342(6155):253-7. https://www.ncbi.nlm.nih.gov/pmc/articles/PMC4018826/

[6] Ye L, Wang J, Tan Y, Beyer AI, Xie F, Muench MO, Kan YW. Genome editing using CRISPR-Cas9 to create the HPFH genotype in HSPCs: An approach for treating sickle cell disease and $\beta$-thalassemia. Proceedings of the National Academy of Sciences. 2016 Sep 20;113(38):10661-5. https://www.ncbi.nlm.nih.gov/pmc/articles/PMC5035856/

\section{Author's Biography}

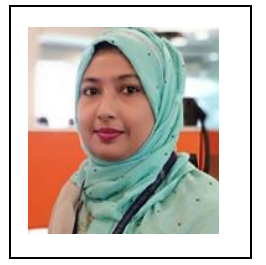

Farjana Akther Noor is a PhD student in the Departement of Biochemistry and Molecular Biology, University of Dhaka, Bangladesh and the Institute for Developing Science and Health Initiatives (ideSHi). She is also a doctoral fellow of the Bangabandhu Science \& Technology Fellowship Trust, Ministry of Science and Technology, Govt. of Bangladesh. She has completed her B.Sc (Honors) and MS from the Department of Biochemistry and Molecular Biology, University of Dhaka. Currently, she is working as a Lecturer, Dept. of Biochemistry and Molecular Biology, Tejgaon College, Dhaka. Her research interest includes Thalassemia, Infectious Diseases, Antimicrobial resistance, and medicinal plants in Bangladesh.

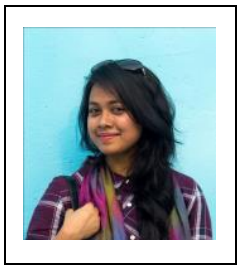

Subarna Sayed Ety is a MSc. Research Student at the Institute for Developing Science and Health Initiatives (ideSHi). She graduated from the department of Biotechnology and Genetic Engineering, Mawlana Bhashani Science and Technology University, Bangladesh in 2016 and is a MSc. Student of the same department. She is doing her MSc. Thesis on "Thalassemia" which is a social 

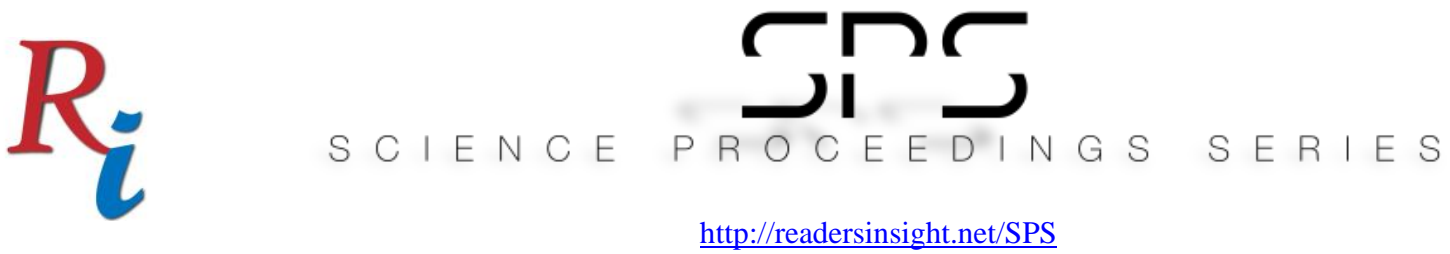

burden for Bangladesh at ideSHi. She has a desire to do her further higher studies on "Genetic Disorder" as well as "Cancer" and wants to contribute her knowledge and skills for human welfare.

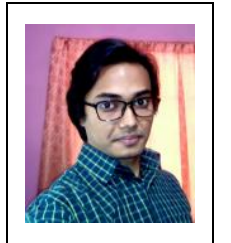

Mohabbat Hossain is a Research Assistant at the Institute for Developing Science and Health Initiatives (ideSHi). He graduated from the department of Genetic Engineering \& Biotechnology, University of Chittagong, Bangladesh in 2015. He completed his MS from the same department in 2016. He did his MS thesis at Molecular Genetics Laboratory, department of Genetic Engineering \& Biotechnology, University of Chittagong, on HbE-beta Thalassemia based on gene mutation and clinical manifestation.

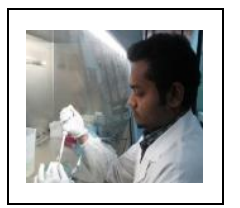

Suprovath Kumar Sarker is Research Fellow \& PhD Student at Institute for Developing Science and Health Initiatives (ideSHi)

s.suprovath@gmail.com

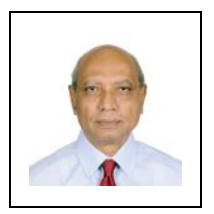

Prof Dr. Syed Saleheen Qadri is Scientific Co-ordinator at Institute for Developing Science and Health Initiatives (ideSHi)

ssqadri@gmail.com

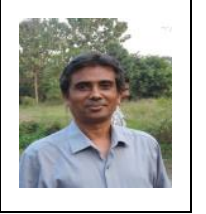

Dr. Kaiissar Mannoor is Senior Scientist and Head at Institute for Developing Science and Health Initiatives (ideSHi)

kaiissar@ideshi.org 